\title{
Ozonation of Indigo Carmine Catalyzed with Fe-Pillared Clay
}

\author{
Miriam Bernal, Rubí Romero, Gabriela Roa, Carlos Barrera-Díaz, \\ Teresa Torres-Blancas, and Reyna Natividad \\ Centro Conjunto de Investigación en Química Sustentable UAEMex-UNAM, Carretera Toluca Atlacomulco Km 14.5, \\ 50200 Toluca, MEX, Mexico \\ Correspondence should be addressed to Reyna Natividad; reynanr@gmail.com
}

Received 13 July 2013; Revised 28 September 2013; Accepted 3 October 2013

Academic Editor: M. Muruganandham

Copyright ( 2013 Miriam Bernal et al. This is an open access article distributed under the Creative Commons Attribution License, which permits unrestricted use, distribution, and reproduction in any medium, provided the original work is properly cited.

\begin{abstract}
The ozonation catalyzed by iron-pillared clays was studied. The degradation of dye indigo carmine (IC) was elected as test reaction. Fe-pillared clays were synthesized by employing hydrolyzed $\mathrm{FeCl}_{3}$ solutions and bentonite. The pillared structure was verified by XRD and by XPS the oxidation state of iron in the synthesized material was established to be +2 . By atomic absorption the weight percentage of iron was determined to be 16. The reaction was conducted in a laboratory scale up-flow bubble column reactor. From the studied variables the best results were obtained with a particle size of 60 microns, $\mathrm{pH}=3$, ozone flow of $0.045 \mathrm{~L} / \mathrm{min}$, and catalyst concentration of $100 \mathrm{mg} / \mathrm{L}$. IC was completely degraded and degradation rate was found to be double when using Fe-PILCS than with ozone alone. DQO reduction was also significantly higher with catalyzed than with noncatalyzed ozonation.
\end{abstract}

\section{Introduction}

A vast amount of water is employed by the textile industry. Because of the dyeing process, the produced wastewater contains strong color and this is reflected as well in a high chemical oxygen demand (COD). It has been estimated that $1-15 \%$ of the dye is lost during dyeing and finishing processes and is released into wastewater $[1,2]$. Even small quantities $\left(<0.005 \mathrm{mg} \mathrm{L}^{-1}\right)$ of dyes in water are unacceptable since the discharge of effluents containing reactive dyes into the environment can interfere with transmission of sunlight into flowing liquid [3]. This causes perturbations in aquatic life and the food web [4]. Thus, an effective and economical technique for removing dyes from textile wastewaters is needed [5]. In this sense, several conventional methods for treating dye effluents have been studied, such as photodegradation [6], adsorption [7], filtration [8], coagulation [9], and biological treatments [10]. However, due to the stability of the molecules of dyes some of these methods are not completely effective and/or viable. In recent years, water treatment based on the chemical oxidation of organic compounds by advanced oxidation processes (AOPs) like ozonation has drawn attention. Ozonation, which is effective, versatile, and environmentally sound, has been tested as a good method for color removal [11]. Ozone is a strong oxidant $\left(E^{\circ}=2.07 \mathrm{~V}\right)$ and reacts rapidly with most of organic compounds [12]. It oxidizes organic pollutants via two pathways: direct oxidation with ozone molecules and/or the generation of free-radical intermediates, such as the ${ }^{\circ} \mathrm{OH}$ radical, which is a powerful, effective, and nonselective oxidizing agent $[13,14]$. However, the degree and rate of oxidation by ozonation is limited by the chemical structure; that is, amines, linear chain alcohols, and ketones are harder to be oxidized by ozone than some aromatic compounds [15]. This has motivated the search for more efficient ozonation processes. In this context, metalcatalyzed ozonations have particularly drawn attention, but water contamination by metals turned out to be a major problem $[16,17]$. The aim of this work is to evaluate the efficiency of ozonation of carmine indigo catalyzed by an Fe-pillared clay. The clay is expected to retain the iron within its structure so that the solution is not contaminated with the metal.

Clays are natural abundant minerals that can be obtained from some mines in high purity [18]. However, it is important to modify them to obtain homogeneous materials that can be used with reliable results. Furthermore, although clay possesses large surface area, this is not accessible due to the strong electrostatic interaction between sheets and charge balancing cations. Thus, to gain access to the interlaminar area large cations ("pillars") should be placed between 
sheets; as a result an increase in the surface area is obtained. Pillared clays are microporous materials that are obtained by exchanging the interlayered cations of layered clays with bulky inorganic polyoxocations, followed by calcinations [1922]. After pillaring, the presence of this new porous structure and the incorporation of new active sites present several possible applications of these materials [23]. As described by Catrinescu et al. [24], there are few examples where iron containing synthetic clays have been tested as solid catalyst to promote the Fenton reaction [24]. Some reports indicate that pillared clays can be used as Fenton catalyst; these reports refer to the catalytic activity imparted by the pillars, which become the actual catalytic sites [25-27]. However, in all the previous research the addition of hydrogen peroxide has been the common reactive added to promote the Fenton reaction. To the authors knowledge there are no reports of the efficiency of ozonation of dyes catalyzed with Fe-pillared clays.

\section{Materials and Methods}

2.1. Reagents. Sulfuric acid, sodium hydroxide, and indigo carmine dye of analytical grade were purchased from SigmaAldrich Chemicals. The acid and the base were used without further purification to adjust the solutions $\mathrm{pH}$ to 3. Purifiedgrade bentonite was supplied by Fisher Scientific.

Ozone was generated in situ from dry air by an ozone generator (Pacific Ozone Technology), with an average ozone production of $0.005 \mathrm{~g} \cdot \mathrm{dm}^{-3}$.

2.2. Synthesis of Fe-PILCs. The Fe-pillared clay (Fe-PILC), used as catalyst, was prepared by a purified-grade bentonite supplied by Fisher Scientific. Fe-PILCs were prepared using $\mathrm{FeCl}_{3} \cdot 6 \mathrm{H}_{2} \mathrm{O}$ and $\mathrm{NaOH}$ solutions according to the method of synthesis reported elsewhere [28]. The former was added to the $\mathrm{NaOH}$ solution to obtain the required $\mathrm{OH} / \mathrm{Fe}$ molar ratio of 2.0. The initial concentration of the Fe salt was $0.2 \mathrm{M}$ and the suspension clay concentration was $0.10 \mathrm{wt} \%$. In order to avoid precipitation of iron species, the $\mathrm{pH}$ was kept constant at 1.78-1.80. The mixture was aged for $4 \mathrm{~h}$ under stirring at room temperature. The pillaring solution was then slowly added to a suspension of bentonite in deionized water. The mixture was kept under vigorous stirring for $12 \mathrm{~h}$ at room temperature. Finally, the solid was washed by vacuum filtration with deionized water until it was chloride-free (conductivity $<10 \mu \mathrm{S} / \mathrm{cm}$ ). Finally, the solid was air-dried $\left(70^{\circ} \mathrm{C}\right)$ and calcined for $2 \mathrm{~h}$ at $400^{\circ} \mathrm{C}$.

2.3. Catalyst Characterization. X-ray diffraction (XRD) patterns were obtained on a Bruker Advance 8 diffractometer using $\mathrm{CuK} \alpha$ radiation at $35 \mathrm{kV}$ and $30 \mathrm{~mA}$. Data were collected over $2 \theta$ range of $3-12^{\circ}$ with a step of $0.04^{\circ} / \mathrm{min}$. X-ray diffraction pattern suggests that the original bentonite was successfully pillared since one peak corresponding to the $\left(\begin{array}{lll}0 & 0 & 1\end{array}\right)$ reflection appeared at small $2 \theta$ angles $\left(2 \theta \approx 4^{\circ}\right)$. According to [28] this result clearly indicates an enlargement of the basal spacing of the clay as consequence of the pillaring process.

The total iron content incorporated into the catalyst was determined by using a SpectrAA 240FS atomic absorption

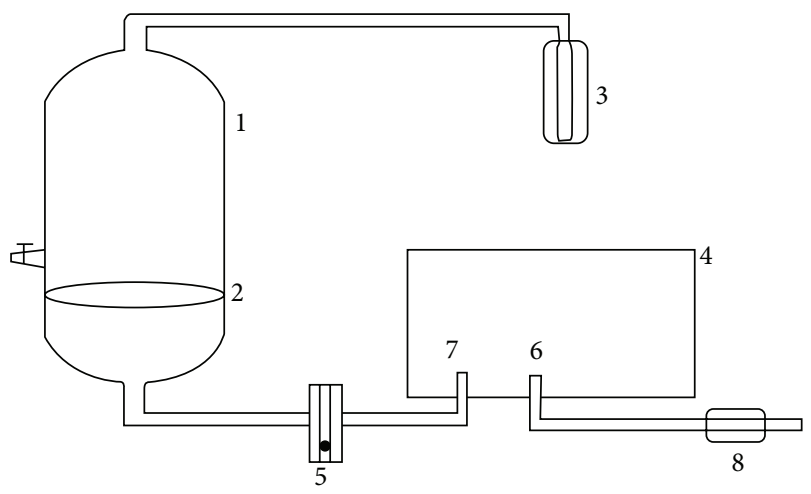

FIGURE 1: Schematic apparatus for the ozonation reaction. (1) Upflow glass bubble column reactor, (2) porous glass (gas diffuser), (3) KI solution trap, (4) ozone generator, (5) flow meter, (6) dry air inlet, (7) ozone output, and (8) air dryer.

spectrophotometer. Before analysis, the samples were dissolved in hydrofluoric acid and diluted to the interval of measurement.

Specific surface area and pore-size distribution were determined by $\mathrm{N}_{2}$ adsorption at $77 \mathrm{~K}$ in a static volumetric apparatus (Micromeritics ASAP 2010 sorptometer). Pillared clays were outgassed prior use at $180^{\circ} \mathrm{C}$ for $16 \mathrm{~h}$ under vacuum of $6.6 \times 10^{-9}$ bar. Specific total surface area was calculated using the Brunauer-Emmett-Teller (BET) equation, whereas specific total pore volume was evaluated from nitrogen uptake at $\mathrm{N}_{2}$ relative pressure of $P / P_{o}=0.99$.

The chemical state of the Fe was analyzed by X-ray photoelectron spectroscopy (XPS, Jeol JPS 9200) with a standard $\mathrm{Mg} \mathrm{K} \alpha$ excitation source $(1253.6 \mathrm{eV})$. Binding energies were calibrated with respect to the carbon signal (C1s) at $285 \mathrm{eV}$.

2.4. Ozonation Experiments. The ozonation experiments were conducted in an up-flow glass bubble column reactor (Figure 1). The gas mixture ozone/air was continuously fed with a flow rate varying from 0.02 to $0.06 \mathrm{~L} \cdot \mathrm{min}^{-1}$ through a gas diffuser with a $2 \mathrm{~mm}$ pore size at the bottom of the reactor. The excess of ozone in the outlet gas was decomposed and trapped in a KI solution. Samples were taken at specific time intervals to be analyzed. Fe-pillared clays were crushed and sieved to a particle size of $60 \mu \mathrm{m}$. All the experiments were carried out at room temperature $\left(19^{\circ} \mathrm{C} \pm 2\right) \cdot \mathrm{pH}$ was adjusted at 3.0 with analytical grade sulfuric acid and sodium hydroxide. In addition to ozone flow rate, the effect of mass of catalyst was also studied in the range of $0-0.1 \% \mathrm{w} / \mathrm{w}$. At all experiments the initial concentration of IC was $1000 \mathrm{mg} / \mathrm{L}$. As control experiments, IC concentration profiles were established by adsorption, ozonation plus bentonite (clay without pillaring) and particles of $\mathrm{Fe}^{\circ}$. For the adsorption experiment, only clay without any ozone supplying was employed in order to discard the removal of IC by physical means. The experiment with only bentonite was conducted with an ozone flow rate of $0.045 \mathrm{~L} \cdot \mathrm{min}^{-1}$ and a bentonite loading of $0.1 \%$. It is worth clarifying that in this case the employed bentonite was not pillared. For the experiment with $\mathrm{Fe}^{\circ}$ particles, 


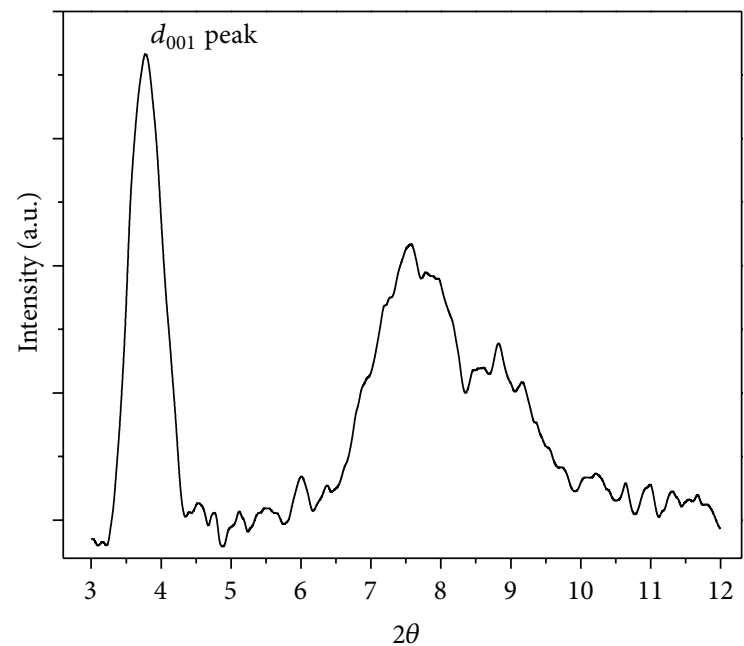

Figure 2: X-ray diffraction pattern of Fe-PILC.

a loading of $0.016 \% \mathrm{w} / \mathrm{w}$ was employed. This iron loading is equivalent to that when using $0.1 \% \mathrm{w} / \mathrm{w}$ of Fe-pillared clay. $\mathrm{Fe}^{\circ}$ particles were synthesized in our laboratory by reducing $0.01 \mathrm{M} \mathrm{Fe}(\mathrm{II})$ sulfate solution with $\mathrm{NaBH}_{4}$ at $\mathrm{pH} 7$ and room temperature. $\mathrm{pH}$ was controlled by adding a $0.5 \mathrm{M} \mathrm{NaOH}$ solution. This was carried out under nitrogen atmosphere and with deaerated water to ensure the production of $\mathrm{Fe}^{\circ}$ particles.

2.5. Chemical Analysis. Concentration of indigo carmine was determined by UV-Vis spectrophotometry technique, using a Perkin-Elmer Model Lambda 25 UV-Vis spectrophotometer with a wavelength range of 190-1100 nm. Samples absorbance was scanned from 200 to $900 \mathrm{~nm}$, and a maximum absorbance at $611 \mathrm{~nm}$ was observed. The scan rate was $960 \mathrm{~nm} \cdot \mathrm{s}^{-1}$. The samples were scanned in a quartz cell with $1 \mathrm{~cm}$ optical path.

In order to establish the oxidation degree of indigo carmine, chemical oxygen demand of samples was determined by means of the American Public Health Association (APHA) standard procedures [29].

\section{Results and Discussion}

3.1. Fe-PILCs Characterization. The XRD pattern of Fe-PILC after calcinations at $400^{\circ} \mathrm{C}$ is shown in Figure 2. This pillared material exhibits a peak at $2 \theta \approx 4^{\circ}$ which is commonly

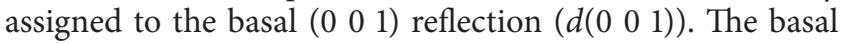
spacing represents the distance between two clay layers, including the thickness of one of the layers. The reflection at low $2 \theta$ values $\left(2 \theta \approx 4^{\circ}\right)$ is a clear indication of the enlargement of the basal spacing of the clay as consequence of the pillaring process, as explained in a previous work [28]. In this pillared clay a broader peak in the range $2 \theta \approx 7-9^{\circ}$ was observed. This can be ascribed to two overlapped peaks, the $\left(\begin{array}{lll}0 & 0 & 2\end{array}\right)$ reflection of the pillared clay and the $\left(\begin{array}{lll}0 & 0 & 1\end{array}\right)$ reflection corresponding to the intercalation of a proportion of monomeric species of small size, thus leading to smaller openings of the clay layers [30].
TABLE 1: Main characteristics of parent clay and Fe-PILC catalyst.

\begin{tabular}{lcccc}
\hline Sample & $d\left(\begin{array}{lll}0 & 0 & 1\end{array}\right)(\AA)$ & $\begin{array}{c}\text { Surface area } \\
\left(\mathrm{m}^{2} / \mathrm{g}\right)\end{array}$ & $\begin{array}{c}\text { Micropore } \\
\text { volume } \\
\left(\mathrm{cm}^{3} / \mathrm{g}\right)\end{array}$ & Fe (wt.\%) \\
\hline Bentonite $\quad-, 9.6^{\mathrm{b}}$ & 35 & 0.0028 & 2.7 \\
Fe-PILC & $24.22^{\mathrm{a}}, 11.6^{\mathrm{b}}$ & 283 & 0.125 & 16 \\
\hline
\end{tabular}

${ }^{\mathrm{a}} 1$ st peak $\left(2 \theta \approx 4^{\circ}\right)$.

b 2 nd peak $\left(2 \theta \approx 7-9^{\circ}\right)$.

Table 1 shows the main textural characteristics, the Fe content of the samples prepared, and the basal spacing corresponding to both the parent clay and the Fe-PILC calcined at $400^{\circ} \mathrm{C}$. As can be seen, the pillared process increases the basal spacing of the clay. The surface area analysis indicates that the pillaring process produces a significant increase in the surface area of parent clay. This can be ascribed to the micropores formation [31].

XPS analysis was performed in order to corroborate the presence of iron and to identify its chemical state. The XPS spectrum corresponding to the Fe $2 \mathrm{p}^{3 / 2}$ narrow scan region of the Fe-PILC was observed (data not shown). According to the National Institute of Standards and Technology (NIST), this peak $(\approx 710 \mathrm{eV})$ corresponds to $\mathrm{FeO}\left(\mathrm{Fe}^{2+}\right)$. This result is coherent with TPR studies that indicated that Fe-pillared clays present only one reduction peak that corresponds to the $\mathrm{Fe}^{3+} \rightarrow \mathrm{Fe}^{2+}$ reduction process [28].

\subsection{Ozonation Experiments}

3.2.1. Effect of Ozone Flow Rate. In an up-flow bubble column the gas flow rate is expected to affect, among other aspects, the rising bubble velocity and therefore the contact time of the gas with the solution. This is finally reflected in the gas mass transferred to solution. Thus, gas flow rate is an important variable in the study of any three-phase system. In this case, to do so, this variable was studied only under the presence of ozone in the range of $0.020-0.060 \mathrm{~L} / \mathrm{min}$. Figure 3 shows the obtained averaged results of two repetitions per flow rate. It can be observed that at all experiments $100 \%$ degradation of indigo carmine (IC) was achieved. The velocity at which this occurs, however, depends on ozone flow rate. It can be observed that depletion of indigo carmine concentration along time increases when increasing of flow rate. Nevertheless, when flow rate is $0.06 \mathrm{~L} \cdot \mathrm{min}^{-1}$ the rate of indigo carmine degradation becomes slower. This means that a maximum of ozone in solution is achieved before this flow rate, and this is observed to happen when a $0.045 \mathrm{~L} \cdot \mathrm{min}^{-1}$ is employed. Therefore, the rest of the experiments were conducted at this flow rate.

3.2.2. Effect of Mass of Catalyst. In order to study the effect of this variable four experiments with their corresponding repetitions were conducted within the catalyst concentration range of $0-0.1 \% \mathrm{w} / \mathrm{w}$ and with an initial concentration of IC at all cases of $1000 \mathrm{mg} / \mathrm{L}$ and an ozone flow rate of $0.045 \mathrm{~L} \cdot \mathrm{min}^{-1}$. All the experiments were carried out at $\mathrm{pH} 3$ 


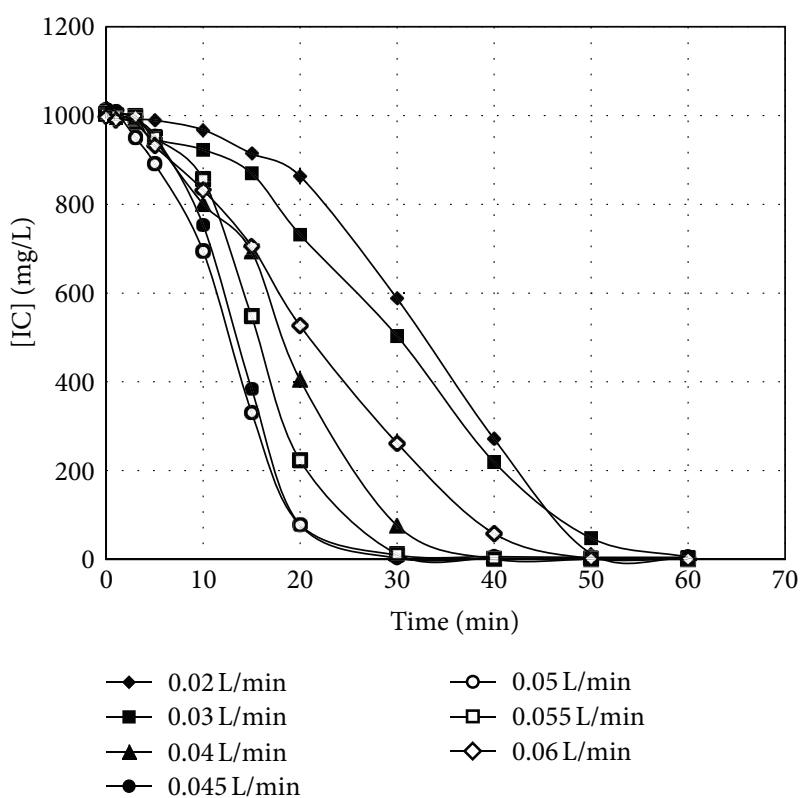

FIGURE 3: Influence of gas flow rate on the indigo carmine concentration.

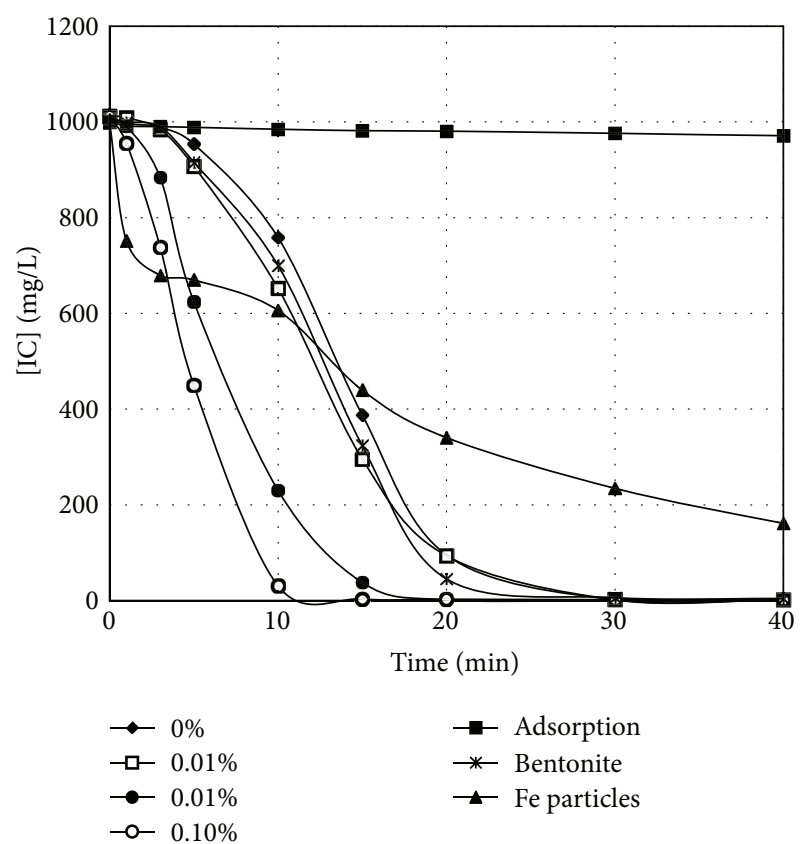

FIgURE 4: Effect of Fe-PILC concentration (\% w/w) and type of catalyst (Fe-PILC, clay without pillaring, and Fe particles) on Indigo carmine concentration.

to avoid the precipitation of Fe [32]. From Figures 4 and 5, the positive effect of the Fe-pillared clay is evident. The presence of the catalyst enhances the ozonation process, and the mass of catalyst has a strong influence over the dye degradation. This increases when mass of Fe-pillared clays increases and this is also an indication of the liquid-solid mass transfer resistance being negligible. It is observed in Figure 4 that by only adding $0.1 \% \mathrm{w} / \mathrm{w}$ of catalyst the IC degradation rate is

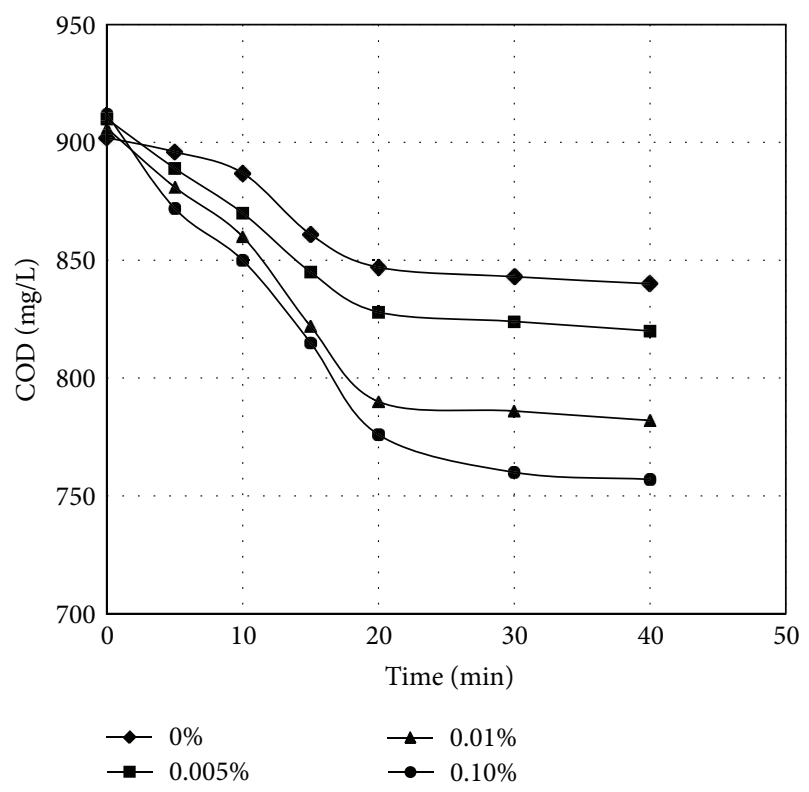

FIGURE 5: Effect of catalyst concentration on chemical oxygen demand (COD).

doubled. Moreover, Figure 5 shows that the use of catalyst not only affects IC degradation rate but also its oxidation degree. Three other plots can be observed in Figure 4. The adsorption experiment confirmed the role of Fe-PILC as catalyst rather than as sorbent. It was found that only $2.9 \%$ of IC is removed by this phenomenon during the time of reaction $(60 \mathrm{~min})$. Also, in Figure 4, the experiment labeled as bentonite further highlights the effect of pillaring since it can be observed that the bentonite alone does not have a significant effect on ozonation rate, which came out to be practically the same when using only ozone. It is worth clarifying that in this case the employed bentonite was not pillared and that its iron content (by nature) was determined by atomic absorption to be $2.7 \%$. Regarding the effect of Fe particles, it can be observed that the initial IC degradation rate is noticeably improved by the presence of this solid. This improvement, however, is not constant and the degradation rate becomes relatively slower after few minutes of reaction. This behavior can be ascribed to the ready availability of Fe for reactions (4) and (5) to occur. It seems, however, that in this case, reaction (4) occurs more rapidly than reaction (6), which implies that after few minutes of reaction $\mathrm{Fe}^{3+}$ species may prevail thus limiting degradation rate.

Figure 5 indicates that the oxidation degree depends on catalyst concentration. To elucidate the species that became resistant to each treatment the UV-Vis spectra of the reacting solution as function of time were analyzed and these are depicted in Figure 6. It can be observed in this figure that the corresponding spectrum to IC presents two absorption bands with maxima at 600 and $340 \mathrm{~nm}$. The former band is characteristic of indigo and the latter is ascribed to auxochromes $\left(\mathrm{N}, \mathrm{SO}_{3}\right)$ joined to the benzene ring. When ozone is applied to the IC solution, it can be observed in Figure 6(a) that the maximum absorbance at $600 \mathrm{~nm}$ decreases and this 


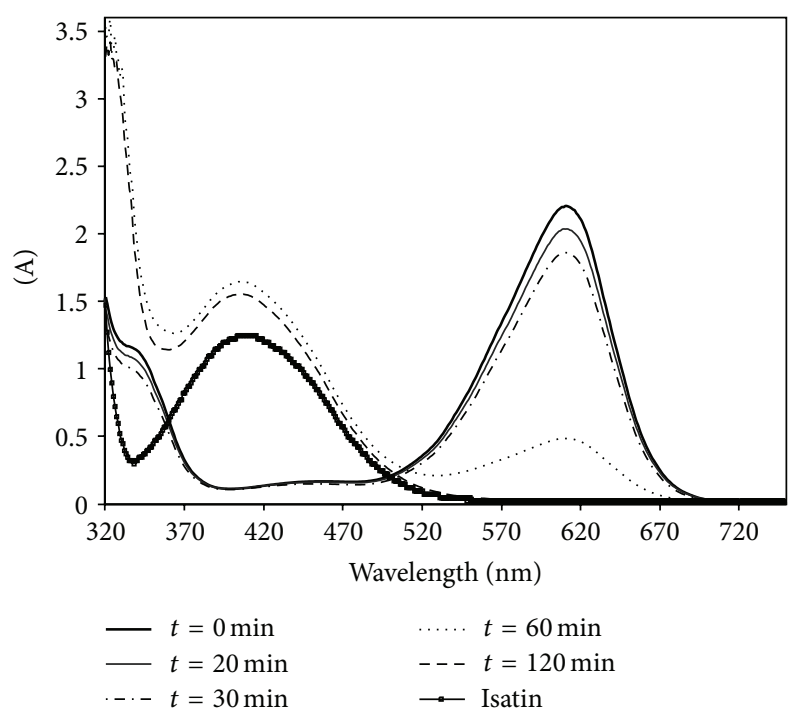

(a)

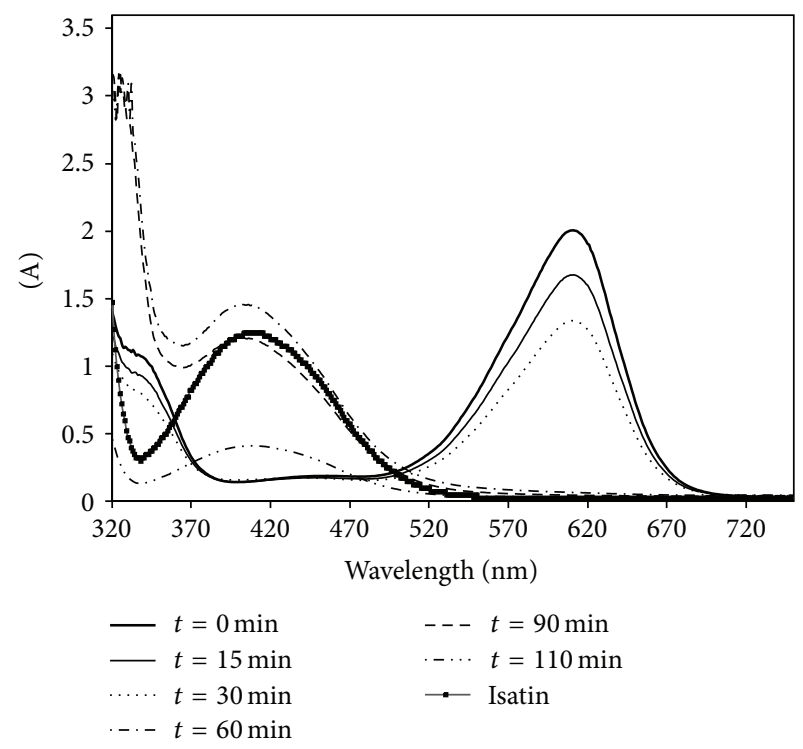

(b)

FIGURE 6: Effect of degradation type and time on UV-Vis spectra. (a) Ozonation alone; (b) ozonation + Fe-pillared clay.

indicates that the characteristic blue color is diminishing also. This may be due to the loss of sulphonate group since this works as auxochrome and therefore increases color intensity. After 40 minutes of reaction a new absorption band appears at $403 \mathrm{~nm}$ and this can be ascribed to a degradation product of IC. This product was identified as isatine by comparison with the absorption spectra of the corresponding standard. After 120 minutes of ozonation treatment only isatine is identified in the solution and no further degradation with ozone only was detected.

Unlike with ozonation alone, it can be observed in Figure 6(b) that when using ozonation + Fe-PILC not only the loss of color is improved but also the degradation of isatine. Until minute 30 , both treatments are very similar. When using Fe-PILC, the absorption band attributed to the IC completely disappears and then the band related to isatine is observed. This diminished up to $72 \%$ of that at 60 minutes.

These results suggest that when only ozone is used the dye is degraded mainly by the direct action of ozone molecules. This, however, does not rule out the production of ${ }^{\circ} \mathrm{OH}$ radicals by means of reaction (1). These radicals may be consumed by reaction (2) rather than by oxidizing the IC. The product of this reaction may be reacting further to obtain $\mathrm{H}_{2} \mathrm{O}_{2}$ [33]:

$$
\begin{gathered}
\mathrm{O}_{3}+\mathrm{H}_{2} \mathrm{O} \longrightarrow 2 \mathrm{OH}^{\bullet}+\mathrm{O}_{2} \\
\mathrm{O}_{3}+\mathrm{OH}^{\bullet} \longrightarrow \mathrm{O}_{2}+\mathrm{HO}_{2}^{\cdot} \longleftrightarrow \mathrm{O}_{2}^{\bullet}+\mathrm{H}^{+} \\
2 \mathrm{OH}_{2}^{\bullet} \longrightarrow \mathrm{O}_{2}+\mathrm{H}_{2} \mathrm{O}_{2}
\end{gathered}
$$

When the ozone is combined with Fe-PILC the intensification of $\mathrm{OH}$ production is expected according the following reaction [34]:

$$
\mathrm{FeO}^{2+}+\mathrm{H}_{2} \mathrm{O}_{2} \longrightarrow \mathrm{Fe}^{3+}+\mathrm{OH}^{\bullet}+\mathrm{OH}^{-}
$$

The ferrous species involved in reaction (4) may be produced by the ferrous species in the pillared clay by means of the following reactions:

$$
6 \mathrm{H}^{+}+\mathrm{O}_{3}+\mathrm{FeO} \longrightarrow \mathrm{FeO}^{2+}+3 \mathrm{H}_{2} \mathrm{O}
$$

$\mathrm{Fe}^{3+}$ species may be going back to $\mathrm{Fe}^{2+}$ by means of the following reaction:

$$
\mathrm{Fe}^{3+}+\mathrm{H}_{2} \mathrm{O}_{2} \longrightarrow \mathrm{Fe}^{2+}+\mathrm{HO}_{2}^{\cdot}+\mathrm{H}^{+}
$$

Therefore, when adding the Fe-PILC to the ozonation process, the oxidation reactions are intensified and so the degradation of IC to isatine and other products is plausible to occur according to Scheme 1 [35].

Figure 7 shows the evolution of $\mathrm{pH}$ with time. It is observed that $\mathrm{pH}$ slightly rises at the beginning of the reaction and this may be ascribed to the expected production of $\mathrm{HO}^{\circ}$ radicals. After the initiation period, $\mathrm{pH}$ drops down to 2 and this may be due to the acid products shown in scheme of reaction (1).

XPS analysis was made to determine the oxidation state of the Fe present in the clay at the end of reaction and it was demonstrated to be $2+$. It is worth noticing that iron leaching was not observed at any point of reaction.

\section{Conclusions}

The degradation of indigo carmine by ozonation and catalyzed ozonation with Fe-pillared clay was studied. The role of the Fe-pillared clay as catalyst was demonstrated. A small amount of the clay allows substantially enhancing the degradation and mineralization of indigo carmine. In the catalyzed ozonation process the reaction occurs faster than 


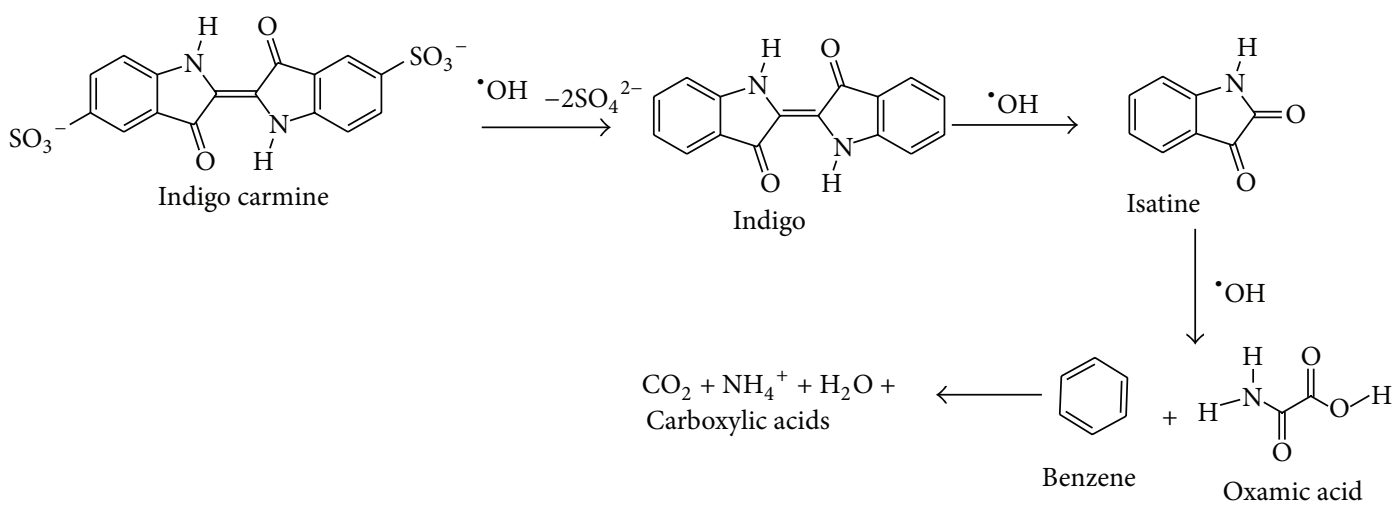

Scheme 1: Plausible mechanism of degradation of indigo carmine by ozonation catalyzed with Fe-pillared clay.

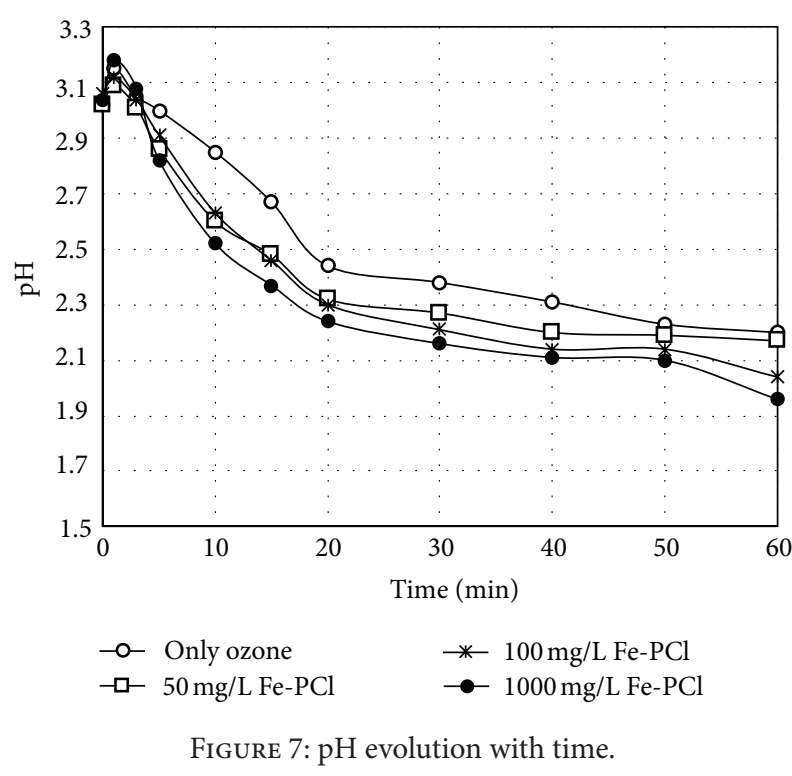

in the noncatalyzed system doubling the reaction rate. The reutilization of the catalyst is feasible since neither leaching or Fe oxidation state changes were detected.

\section{Conflict of Interests}

The authors declare that there is no conflict of interests regarding the publication of this paper.

\section{Acknowledgment}

The authors are grateful to CONACYT for financial support of Project 168305. Bernal is grateful to CONACYT for scholarship.

\section{References}

[1] N. Daneshvar, M. Rabbani, N. Modirshahla, and M. A. Behnajady, "Photooxidative degradation of Acid Red 27 in a tubular continuous-flow photoreactor: influence of operational parameters and mineralization products," Journal of Hazardous Materials, vol. 118, no. 1-3, pp. 155-160, 2005.

[2] N. Daneshvar, H. Ashassi-Sorkhabi, and A. Tizpar, "Decolorization of orange II by electrocoagulation method," Separation and Purification Technology, vol. 31, no. 2, pp. 153-162, 2003.

[3] K. Santhy and P. Selvapathy, "Removal of reactive dyes from wastewater by adsorption on coir pith activated carbon," Bioresource Technology, vol. 97, no. 11, pp. 1329-1336, 2006.

[4] Z. Aksu, "Reactive dye bioaccumulation by Saccharomyces cerevisiae," Process Biochemistry, vol. 38, no. 10, pp. 1437-1444, 2003.

[5] B. Armagan, O. Ozdemir, M. Turan, and C. Elik, "Adsorption of negatively charged azo dyes onto surfactant-modified sepiolite," Journal of Environmental Engineering, vol. 129, no. 8, pp. 709715, 2003.

[6] P. Esparza, M. E. Borges, L. Díaz, and M. C. Alvarez-Galván, "Photodegradation of dye pollutants using new nanostructured titania supported on volcanic ashes," Applied Catalysis A, vol. 388, no. 1-2, pp. 7-14, 2010.

[7] R. Gong, Y. Ding, M. Li, C. Yang, H. Liu, and Y. Sun, "Utilization of powdered peanut hull as biosorbent for removal of anionic dyes from aqueous solution," Dyes and Pigments, vol. 64, no. 3, pp. 187-192, 2005.

[8] F. I. Hai, K. Yamamoto, F. Nakajima, and K. Fukushi, "Removal of structurally different dyes in submerged membrane fungi reactor-Biosorption/PAC-adsorption, membrane retention and biodegradation," Journal of Membrane Science, vol. 325, no. 1, pp. 395-403, 2008.

[9] J.-W. Lee, S.-W. Choi, R. Thiruvenkatachari, W.-G. Shim, and H. Moon, "Evaluation of the performance of adsorption and coagulation processes for the maximum removal of reactive dyes," Dyes and Pigments, vol. 69, no. 3, pp. 196-203, 2006.

[10] N. P. Tantak and S. Chaudhari, "Degradation of azo dyes by sequential Fenton's oxidation and aerobic biological treatment," Journal of Hazardous Materials, vol. 136, no. 3, pp. 698-705, 2006.

[11] S. Song, J. Yao, Z. He, J. Qiu, and J. Chen, "Effect of operational parameters on the decolorization of C.I. Reactive Blue 19 in aqueous solution by ozone-enhanced electrocoagulation," Journal of Hazardous Materials, vol. 152, no. 1, pp. 204-210, 2008.

[12] S. M. D. A. G. Ulson de Souza, K. A. Santos Bonilla, and A. A. Ulson de Souza, "Removal of COD and color from hydrolyzed 
textile azo dye by combined ozonation and biological treatment," Journal of Hazardous Materials, vol. 179, no. 1-3, pp. 3542, 2010.

[13] B. Merzouk, B. Gourich, K. Madani, C. Vial, and A. Sekki, "Removal of a disperse red dye from synthetic wastewater by chemical coagulation and continuous electrocoagulation. A comparative study," Desalination, vol. 272, no. 1-3, pp. 246-253, 2011.

[14] E. Guinea, E. Brillas, F. Centellas, P. Cañizares, M. A. Rodrigo, and C. Saez, "Oxidation of enrofloxacin with conductivediamond electrochemical oxidation, ozonation and Fenton oxidation. A comparison," Water Research, vol. 43, no. 8, pp. 2131-2138, 2009.

[15] L. A. Bernal-Martínez, C. Barrera-Díaz, C. Solís-Morelos, and R. Natividad, "Synergy of electrochemical and ozonation processes in industrial wastewater treatment," Chemical Engineering Journal, vol. 165, no. 1, pp. 71-77, 2010.

[16] M. Koch, A. Yediler, D. Lienert, G. Insel, and A. Kettrup, "Ozonation of hydrolyzed azo dye reactive yellow 84 (CI)," Chemosphere, vol. 46, no. 1, pp. 109-113, 2002.

[17] K. Pachhade, S. Sandhya, and K. Swaminathan, "Ozonation of reactive dye, Procion red MX-5B catalyzed by metal ions," Journal of Hazardous Materials, vol. 167, no. 1-3, pp. 313-318, 2009.

[18] S. Navalon, M. Alvaro, and H. Garcia, "Heterogeneous Fenton catalysts based on clays, silicas and zeolites," Applied Catalysis B, vol. 99, no. 1-2, pp. 1-26, 2010.

[19] V. Rives and M. A. Ulibarri, "Layered double hydroxides $(\mathrm{LDH})$ intercalated with metal coordination compounds and oxometalates," Coordination Chemistry Reviews, vol. 181, no. 1, pp. 61-120, 1999.

[20] A. Czímerová, J. Bujdák, and R. Dohrmann, “Traditional and novel methods for estimating the layer charge of smectites," Applied Clay Science, vol. 34, no. 1-4, pp. 2-13, 2006.

[21] E. M. Serwicka and K. Bahranowski, "Environmental catalysis by tailored materials derived from layered minerals," Catalysis Today, vol. 90, no. 1-2, pp. 85-92, 2004.

[22] A. Vaccari, "Preparation and catalytic properties of cationic and anionic clays," Catalysis Today, vol. 41, no. 1-3, pp. 53-71, 1998.

[23] A. Gil, L. M. Gandía, and M. A. Vicente, "Recent advances in the synthesis and catalytic applications of pillared clays," Catalysis Reviews, vol. 42, no. 1-2, pp. 145-212, 2000.

[24] C. Catrinescu, C. Teodosiu, M. Macoveanu, J. Miehe-Brendlé, and R. le Dred, "Catalytic wet peroxide oxidation of phenol over Fe-exchanged pillared beidellite," Water Research, vol. 37, no. 5, pp. 1154-1160, 2003.

[25] S. Perathoner and G. Centi, "Wet hydrogen peroxide catalytic oxidation (WHPCO) of organic waste in agro-food and industrial streams," Topics in Catalysis, vol. 33, no. 1-4, pp. 207-224, 2005.

[26] L. F. Liotta, M. Gruttadauria, G. D. Carlo, G. Perrini, and V. Librando, "Heterogeneous catalytic degradation of phenolic substrates: catalysts activity," Journal of Hazardous Materials, vol. 162, no. 2-3, pp. 588-606, 2009.

[27] G. Centi and S. Perathoner, "Catalysis by layered materials: a review," Microporous and Mesoporous Materials, vol. 107, no. 12, pp. 3-15, 2008.

[28] J. L. Valverde, A. Romero, R. Romero, P. B. García, M. L. Sánchez, and I. Asencio, "Preparation and characterization of Fe-PILCS. Influence of the synthesis parameters," Clays and Clay Minerals, vol. 53, no. 6, pp. 613-621, 2005.
[29] American Public Health Association American Water Works Association/Water Environment Federation, Standard Methods for the Examination of Water and Wastewater, American Public Health Association American Water Works Association/Water Environment Federation, Washington, DC, USA, 20th edition, 1998.

[30] L. S. Cheng, R. T. Yang, and N. Chen, "Iron oxide and chromia supported on titania-pillared clay for selective catalytic reduction of nitric oxide with ammonia," Journal of Catalysis, vol. 164, no. 1, pp. 70-81, 1996.

[31] C. Pesquera, F. Gonzalez, I. Benito, S. Mendioroz, and J. A. Pajares, "Synthesis and characterization of pillared montmorillonite catalysts," Applied Catalysis, vol. 69, no. 1, pp. 97-104, 1991.

[32] D. Zhao, C. Ding, C. Wu, and X. Xu, "Kinetics of ultrasoundenhanced oxidation of p-nitrophenol by fenton's reagent," Energy Procedia A, vol. 16, pp. 146-152, 2012.

[33] M. Hernández-Ortega, T. Ponziak, C. Barrera-Díaz, M. A. Rodrigo, G. Roa-Morales, and B. Bilyeu, "Use of a combined electrocoagulation-ozone process as a pre-treatment for industrial wastewater," Desalination, vol. 250, no. 1, pp. 144-149, 2010.

[34] T. Loegager, J. Holcman, K. Sehested, and T. Pedersen, "Oxidation of ferrous ions by ozone in acidic solutions," Inorganic Chemistry, vol. 31, no. 17, pp. 3523-3529, 1992.

[35] C. Flox, S. Ammar, C. Arias, E. Brillas, A. V. Vargas-Zavala, and R. Abdelhedi, "Electro-Fenton and photoelectro-Fenton degradation of indigo carmine in acidic aqueous medium," Applied Catalysis B, vol. 67, no. 1-2, pp. 93-104, 2006. 

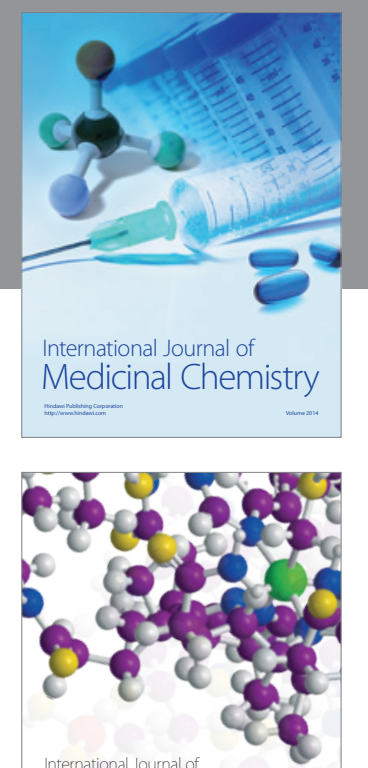

\section{Carbohydrate} Chemistry

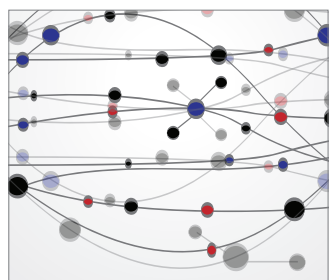

The Scientific World Journal
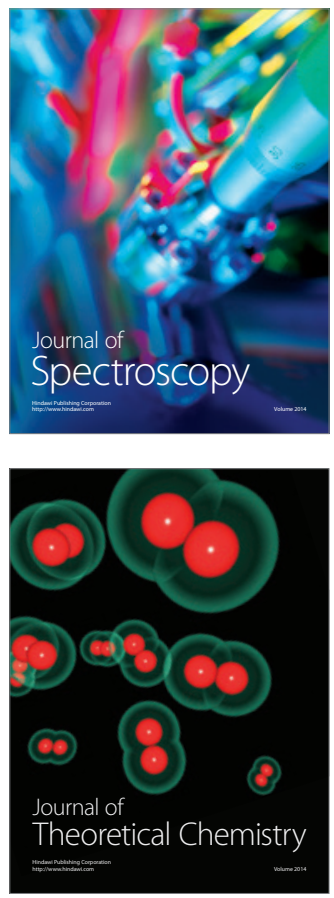
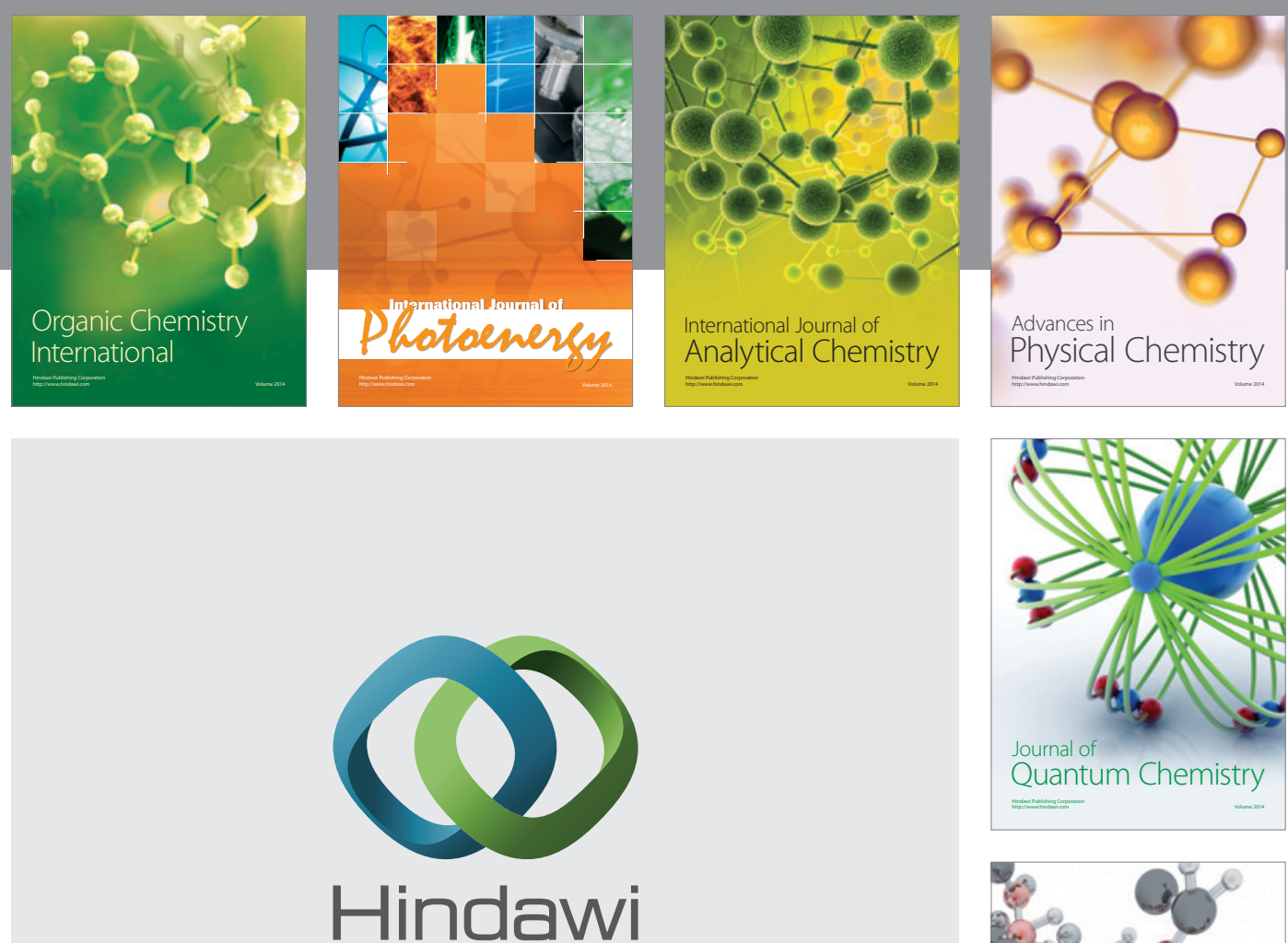

Submit your manuscripts at

http://www.hindawi.com

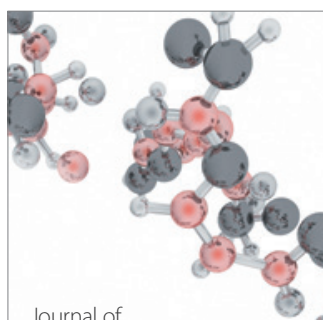

Analytical Methods

in Chemistry

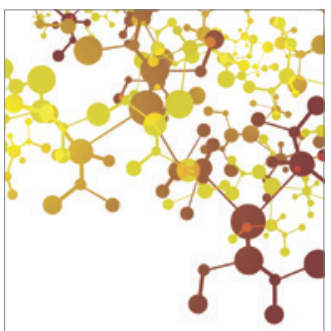

Journal of

Applied Chemistry

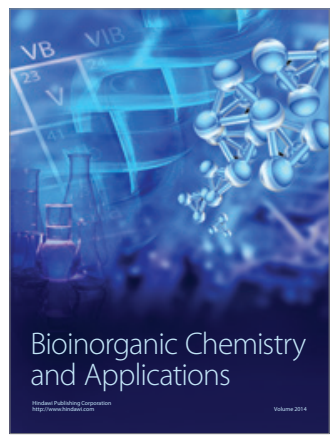

Inorganic Chemistry
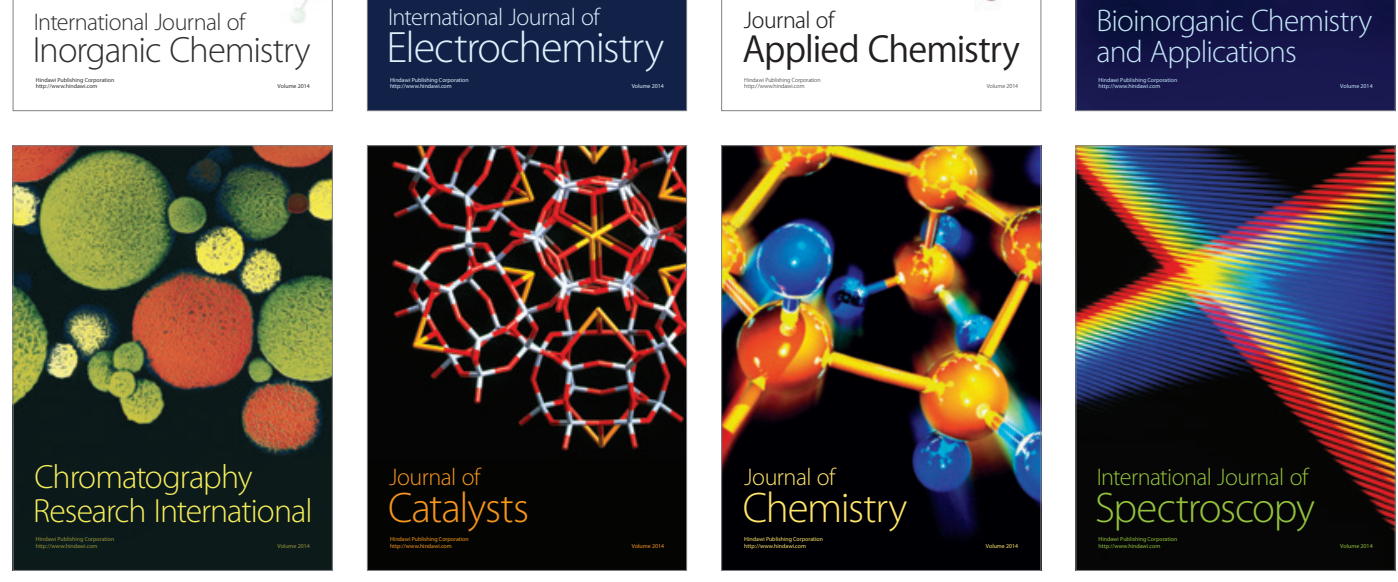